\title{
Cancer of the Mobile Tongue: About 29 Cases Collected at the ENT and CCF Service of the University Hospital Centre of Fann (Dakar/Senegal)
}

\author{
Ndour Ngor ${ }^{1 *}$, Ahmed Houra ${ }^{1}$, Ndiaye Ciré ${ }^{1}$, Amelle Lokossou ${ }^{1}$, Younes Hussen ${ }^{1}$, Dieye Abdoulaye ${ }^{1}$, Diallo Mamadou \\ Diouldé $^{1}$, Niang Fallou ${ }^{1}$, Ndiaye Malick ${ }^{2}$, Tall Abdourahmane ${ }^{1}$ and Ndiaye Issa Cheikh ${ }^{1}$
}

${ }^{1}$ Department of ENT, Fann University Hospital Centre, Senegal

${ }^{2}$ Department of ENT and CCF service, Diamniadio children's Hospital, Senegal

*Corresponding author: Ndour Ngor, Department of ENT and CCF Service, Fann University Hospital Centre, Senegal

\begin{abstract}
Summary
Objectives: We report the epidemiological, clinical, paraclinical and therapeutic data of mobile tongue cancers operated in the ENT and CCF service of the University Hospital of Fann (Dakar/Senegal).

Patients and methods: This were a monocentric retrospective study, conducted at the ENT and cervico-facial surgery department of the CHNU of Fann from 1 January 2009 to 31 December 2018, i.e. 10 years. All patients operated during this period with cancer of the mobile tongue with histological confirmation were included.

Results: A total of 29 records were collected. They were 17 males and 12 females, for a sex ratio of 1.07 . The mean age of the patients was 52 years with a median age of 49 years. Tobacco intoxication was found in 5 patients or $17.24 \%$ of cases. Isolated glossodynia was the most frequent symptom, (27.5\%) of the cases. The lesion was ulceroburging in $55 \%$ of cases and was located on the right lateral edge of the mobile tongue in $72.4 \%$ of cases. As part of the extension workup, CT scan was performed in 4 patients. Panendoscopy was performed in 27 patients or $93.1 \%$ of cases. The tumor was classified as T3- T4 in $61.9 \%$ of cases and N0-N1 in $58.5 \%$ of cases. Hemi glossectomy was the most common procedure performed $(48.27 \%)$ associated with complete unilateral functional curettage (41.3\%). The anatomopathological result of the operation was in favor of squamous cell carcinoma in $100 \%$ of cases. Nine of our patients had benefited from additional treatment after surgery, i.e. $31 \%$ of cases.
\end{abstract}

Conclusion: Despite surgical advances and radiotherapy, treatment is often a failure for many at-risk patients. We conclude from this work that the prognosis is significantly better in patients diagnosed at an early stage.

Keywords: Mobile tongue; squamous cell carcinoma; glossectomy

Abbreviations: ADT: Aerodigestive Tract; SPSS: Statistical Package for Social Science

\section{Introduction}

Cancers of the tongue are the most common cancers of the oral cavity with poor survival [1,2]. The main risk factors are mainly tobacco and alcohol intoxication and poor oral health, but other carcinogens are emerging: viral (HPV) and environmental (asbestos) factors [3-5]. Like all cancers of the upper aerodigestive tract (ADT), squamous cell carcinoma is the most common histological type of cancer of the tongue in $95 \%$ of cases. It generally occurs in males from the age of 55 onwards. It is locally aggressive, and locoregional evolutionary pursuits are frequent
[6-8]. Pre-therapeutic evaluation and monitoring of these cancers has been improved in recent decades by advances in medical imaging (MRI). Treatment is based on a combination of surgery and radiotherapy. Mortality from this cancer remains high: $40 \%$ survival in 5 years at all stages [2]. The aim of this study was to report the epidemiological, clinical, paraclinical and therapeutic aspects of mobile tongue cancer that has undergone surgery in the ENT and CCF department of the Fann University Hospital (Dakar/ Senegal). 


\section{Patients and Methods}

This is a retrospective study conducted at the ENT and CCF service of the CHNU of Fann (Dakar/Senegal) on patients operated on for mobile tongue cancer during the period from 1 January 2009 to 31 December 2018. Excluded from this study were the records of patients with cancer of the base of the tongue, patients who were received as second hand after a first operation in another structure and incomplete records. The parameters studied were age, sex, promoting factors, clinical and paraclinical signs, type of surgery, histological result and complementary treatment. The data obtained were entered into Excel and analyzed by the statistical package for social science (SPSS) version 20.

\section{Results}

In 10 years, we have collected 29 cases of mobile tongue cancer operated on. We noted 17 male subjects, i.e. $58.6 \%$ of the cases and 12 female subjects, i.e. $41.4 \%$ of the cases with a sex ratio of 1.41 . The sex ratio was 1.41 . The mean age of our patients was 52 years with extremes ranging from 14 to 78 years with a median age of 49 years. Alcohol and smoking intoxication were found in 3 patients (Table 1). The average time of disease progression was 5.6 months with extremes ranging from 2 months to 12 months. Isolated glossodynia was the main reason for consultation $(27.5 \%)$, (Table 2). Macroscopically, the lesion was ulcerous and budding (Figure 1) in $55 \%$ of cases, ulcer infiltrating in $17.2 \%$ of cases, ulcerous budding and infiltrating in $10.3 \%$ of cases, ulcerous budding and necrotic in $6.8 \%$ of cases, ulcerated in $3.4 \%$ of cases, infiltrating in $3.4 \%$ of cases and ulcerous budding and necrotic-infiltrating in $3.4 \%$ of cases. This lesion was located on the right lateral edge of the mobile tongue in 21 patients, i.e. $72.4 \%$ of cases. Palpation showed an extension towards the floor of the mouth in 8 patients, towards the base of the tongue without going beyond the midline in 2 patients and towards the tip of the tongue and the midline in 4 patients. The size of the lesion was estimated in 20 patients or $68.9 \%$ of cases. It averaged $3.8 \mathrm{~cm}$ with extremes of $2 \mathrm{~cm}$ to $5 \mathrm{~cm}$. Palpable lymphadenopathy was found in $65.5 \%$ of cases. As part of the extension workup, a CT scan of the oral cavity (Figure 2) and cervico-thoracic cavity was performed only in 4 patients, none of the patients in our study benefited from magnetic resonance imaging. Chest X-rays were performed in all our patients. A first panendoscopy of the upper ADT was performed in 27 patients, i.e. $93.1 \%$ of the cases. Histological analysis was in favor of squamous cell carcinoma in $93.1 \%$ of cases. At the end of the extension assessment, the lesions were classified as T3-T4 in $61.9 \%$ of cases and N0-N1 in 58.5\% of cases according to the TNM classification of 2017. Haemiglossectomy was the most common surgical procedure performed (48.27\%) followed by pelviglossectomy (20.68\%) (Table 3). Four patients had received a flap as part of tongue reconstruction. Seven patients in our study had received postoperative radiotherapy, $24.13 \%$ of the cases, and 7 other patients had received chemotherapy, of which in 2 patients it was neo-adjuvant, in 2 others adjuvant chemotherapy and in 3 patients it was palliative. The histological findings of the surgical specimen and its excision product were in favor of squamous cell carcinoma in all our patients. For the surgical specimen, the resection margins were healthy in $55 \%$ of cases and invaded in $13.79 \%$ of cases. The excision product was the site of a carcinomatous focus in $58.62 \%$ of cases and free of any lesion in $24.13 \%$ of cases. For an average delay of 9 months with extremes ranging from 1 to 32 months, we had noted 6 cases of complete remission, 8 cases of progressive continuation, no cases of recurrence and 15 patients lost sight of after the complete healing of the surgical wound.

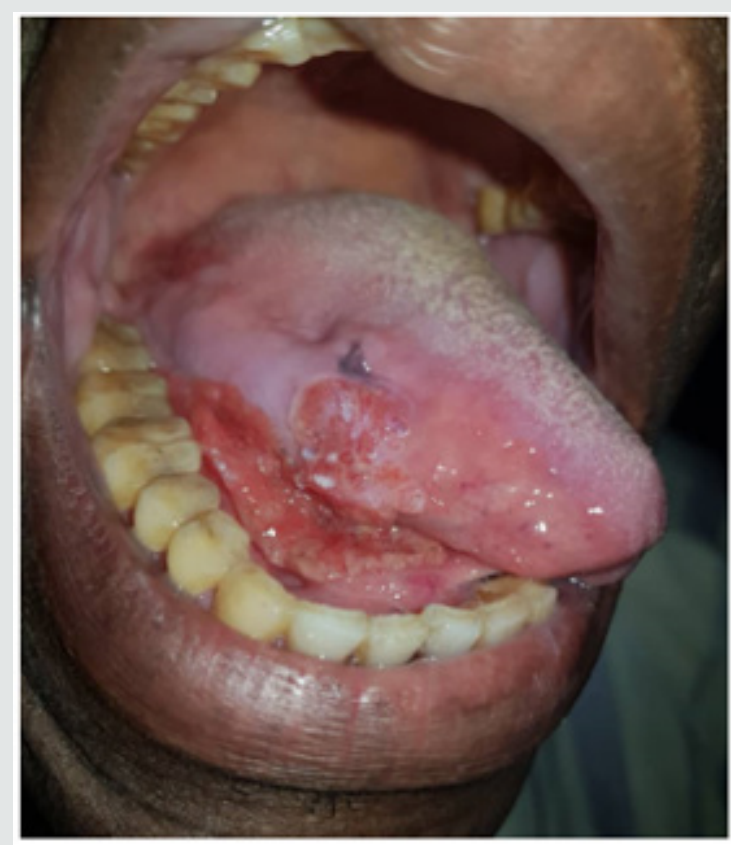

Figure 1: Ulcer-budding lesion of the right lateral border extend to oral floor area.

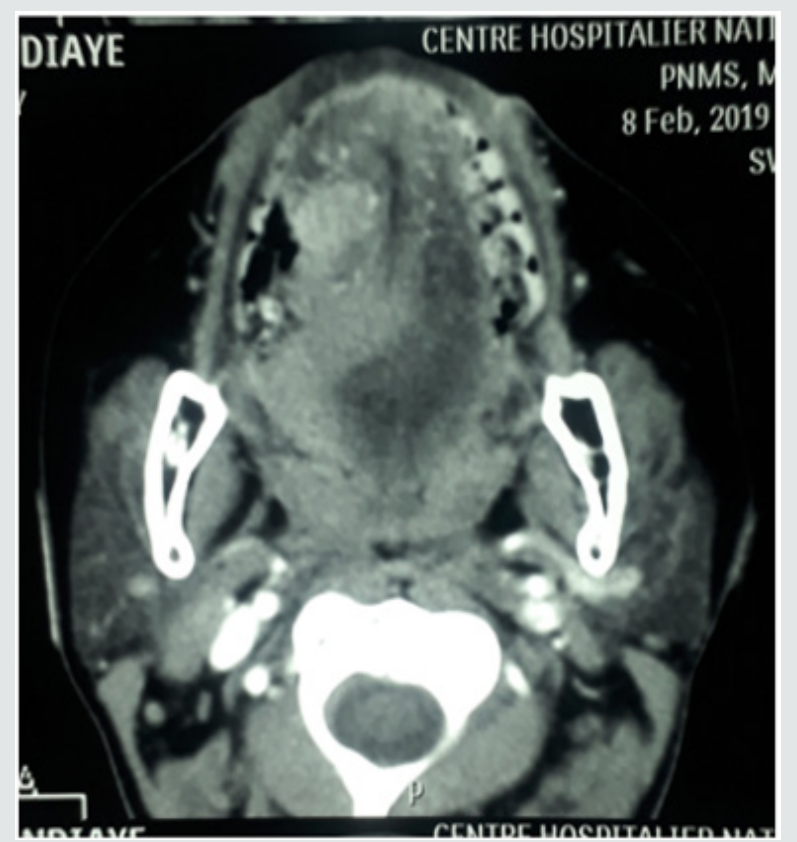

Figure 2: CT scan of the oral cavity: axial section showing a malignant lesion of the mobile tongue. 
Table 1: The different risk factors found in patients.

\begin{tabular}{|c|c|c|}
\hline Risk Factors & Numbers (n=) & Percentages (\%) \\
\hline Alcohol Tobacco intoxication & 3 & 10 \\
\hline Tobacco intoxication & 2 & 6.9 \\
\hline Recurrent oral aphthosis & 1 & 3.4 \\
\hline Larynx cancer history & 1 & 3.4 \\
\hline No risk factors found & 22 & 75.8 \\
\hline
\end{tabular}

Table 2: Distribution of Patients by Reasons for Visit.

\begin{tabular}{|c|c|c|}
\hline Reasons for Visit & Number & Percentages (\%) \\
\hline Isolated glossodynia & 8 & 27.5 \\
\hline Glossodynia+ lingual ulceration & 6 & 20.6 \\
\hline $\begin{array}{c}\text { Glossodynia+ lingual ulceration+ } \\
\text { otalgia + swallowing disorder }\end{array}$ & 6 & 20.6 \\
\hline $\begin{array}{c}\text { Glossodynia+Otalgia } \\
\text { Lingual ulceration + laterocervical } \\
\text { tumefaction }\end{array}$ & 3 & 10.3 \\
\hline $\begin{array}{c}\text { Lingual ulceration + otalgia + } \\
\text { swallowing disorder }\end{array}$ & 1 & 6.9 \\
\hline $\begin{array}{c}\text { Glossodynia+lingual } \\
\text { ulceration+otalgia }\end{array}$ & 1 & 3.4 \\
\hline $\begin{array}{c}\text { Glossodynia+laterocervical } \\
\text { tumefaction+otalgia }\end{array}$ & 1 & 3.4 \\
\hline Swallowing disorder & 1 & 3.4 \\
\hline
\end{tabular}

Table 3: Distribution of Patients by Surgical Treatment.

\begin{tabular}{|c|c|c|}
\hline Surgical Treatment & Numbers (n=) & Percentages (\%) \\
\hline Hemi glossectomy & 14 & 48.2 \\
\hline Pelvic glossectomy & 6 & 20.6 \\
\hline Partial glossectomy & 5 & 10.3 \\
\hline Subtotal glossectomy & 2 & 6.8 \\
\hline $\begin{array}{c}\text { Glossopelvimandibulectomy } \\
\text { by BPTM }\end{array}$ & 2 & 6.8 \\
\hline Total & 29 & 100 \\
\hline
\end{tabular}

\section{Discussion}

The oral cavity is the most common location for cancers of the upper aerodigestive tract (QDT). Worldwide, cancer of the oral cavity accounts for 275,000 new cases per year, i.e. $54 \%$ of all cases of cancers of the upper aerodigestive tract, of which $40-50 \%$ occur in the tongue $[1,6]$. Tongue cancer represents $1.6 \%$ of all cancers in the USA [9], $1.4 \%$ in Tunisia [10] and $2 \%$ worldwide [11]. In our study the sex ratio was 1.41 in favor of the male sex. This is consistent with the results of Diombana et al. [12], Bousaadani et al. [1], Beldgadi et al. [13]. However, in some series, the sex ratio tends to shift in favour of the female sex due to the increase in the number of women who smoke from day to day [14-16]. Cancer of the tongue is a cancer of the mature subject. However, cases below the age of 30 are not exceptional, as is the case in our study with a 14-year-old patient. Bouykhelef et al. [17] report a mean age of 57 years with extremes from 34 to 80 years, EL idrissi et al. [14] report a mean age of 60 years with extremes from 36 to 80 years. In our series, we found a mean age of 52 years with extremes from 14 to 78 years.
These results are close to those in the literature [13]. Considered since 1954 as a risk factor for upper ADT neoplasia, through the production of irritating substances and polycyclic aromatic hydrocarbons, tobacco intoxication is found in 60 to $80 \%$ of patients with tongue cancer $[2,18,19]$. Rothmann and Keller [20] specify the relationship between the intensity of tobacco consumption and the appearance of oral cavity cancer: for a risk of 1 in non-smokers, it is 1.52 if consumption is 20 cigarettes/d and 2.43 if consumption exceeds 40 cigarettes/d. Laurent [21], in a series of 70 patients with oral cancer between 1992 and 2002, found that $60 \%$ of patients were smokers with a consumption of more than one pack a day. Aksu [16] found $81 \%$ smokers, of which $38 \%$ are heavy smokers ( $\geq$ 20 cigarettes /d). The effects of smoking are potentiated by alcohol intoxication. In our study, alcohol-smoking intoxication was found in $10.3 \%$ of cases and smoking intoxication alone in $6.9 \%$ of cases. This low percentage could be explained by the lack of sincerity in the declaration of this subject or the existence of other risk factors such as viral factors (HPV) and poor oral health. The last one would probably be related to often poor socio-economic conditions, which constituted $80.5 \%$ in Bouyekhelef [17] and 58.5\% in EL Idrissi [14]. However, Rakotoarison [22] in his observation found a case of squamous cell carcinoma of the tongue due to chronic irritation of a poorly adapted dental prosthesis. In our series, we reported a case of squamous cell carcinoma in a patient previously treated by radiation for laryngeal cancer. In the literature, cases of tongue cancer on precancerous lesions were reported in 5\% according to [23]. These are epithelial alterations that may or may not progress to squamous cell carcinoma. They are observed mainly in men over 50 years of age and are associated with alcohol and tobacco consumption. The role of pollution and HPV are still being discussed [23]. They are mainly represented by leukoplakia and dysplasia. Cancers of the tongue are often discovered late because of the discretion of their symptomatology $[2,24,25]$. In our series, this delay was on average 5.6 months, which corroborates the results of El Idrissi [14]. This delay in consultation may be linked to the neglect and trivialization of symptoms by our patients or to the use of traditional medicine.

In our series, isolated glissandi were the main reason for consultation in $27.5 \%$ of cases, followed by glissandi associated with lingual ulceration in $20.6 \%$ of cases. For Belgadi [13] and Laurent [21], lingual ulceration was the main reason for consultation. In the literature the electroburning form is the most frequent form of cancer of the mobile tongue $[16,17]$. In our study, we found an electroburning form in 55\% of cases followed by an ulcer infiltrating form in $17.2 \%$ of cases. The extension is preferentially in the anteroposterior direction but also in the thickness of the lingual muscle mass. The anterior and lateral buccal floor, the lower gum, the base of the tongue and the elements of the tonsil chamber are successively examined. In the literature, examination of the lymph node areas reveals lymph node invasion (the submaxillary, sub digastric and supra omohyoid nodes) in the order of $20 \%$ for $\mathrm{T} 1,50 \%$ for $\mathrm{T} 2$ and $\mathrm{T} 3$, and $75 \%$ for T4 [17,23]. Node involvement was found in $65.5 \%$ of the cases in our study. Brasnu et al. [26] recommend that as part of the extension assessment, MRI, PET scan, pan endoscopy, CT scan with contrast agent injection and 
metastatic assessment (thoracic CT scan, abdominal ultrasound and esophageal microscopy) should be performed. MRI may be offered in first line for lingual carcinoma, especially if an extension to the floor of the mouth or to the midline is suspected by palpation $[2,17,18]$. These different examinations could not be performed in our series due to the low socio-economic standard of living of our patients. At the end of the clinical examination and the extension assessment, EL Idrisi [14] had concluded in its work at a rate of $83 \%$ for $\mathrm{T} 1$ and $\mathrm{T} 2$ tumors. In our series, patients were classified as T3-T4 in $61.9 \%$ of cases and N0-N1 in $28.5 \%$ of cases. This result can be explained by the delay in consultation and the aggressiveness of lingual cancer. Therapeutically, the most common surgical procedure performed in our study was hemi glossectomy in $48.27 \%$ of cases and pelviglossectomy in $20.68 \%$ of cases. This is due to the fact that more than the majority of our patients were diagnosed at a late stage (61.9\% T3-T4). EL Idrissi [14] performed in its series 50\% partial glossectomy and $16.6 \%$ hemi glossectomy. Hicks [27] performed partial glossectomy in $74.7 \%$ followed by hemi glossectomy in $14 \%$ of cases. Post-operative radiotherapy is indicated in cases of invaded resection limits, vascular emboli, perineural invasion, lymph node involvement with capsular rupture for all tumors except T1. It is associated with concomitant platinumbased chemotherapy in the case of positive cross-examinations and extra capsular lymph node extension [4]. In our series, only seven patients received post-operative radiotherapy because at that time there was only one radiotherapy center in our country for all cancer patients.

\section{Conclusion}

Despite surgical advances and radiotherapy, treatment is often a failure for many at-risk patients. We conclude from this work that the prognosis is significantly better in patients diagnosed at an early stage.

\section{References}

1. Bousaadani AE, Adou elfadl M, Abada R (2015) Cancer of the tongue epidemiology and management. African Cancer Journal 1-5.

2. Prades JM, Schmitt T, Timoshenko A (2004) Cancer of the tongue. CME ear nose and throat pp. 35-55.

3. Brugère J (1987) Cancer of the upper aerodigestive tract. Paris Flammarion Médecine sciences pp. 491.

4. Baujat B, Périé S, Bardet É, Lacau St Guily J (2014) Cancers of the oral cavity. Update Bull Cancer 101: 424-428.

5. Fouret P, Monceau G, Temam S (1997) Human papillomavirus in head and neck squamous cell carcinoma in nonsmokers. Arch Otol Laryngol Head Neck Surg 123: 513-516.

6. Paré A, Joly A (2017) Oral cancer risk factors and management. Press Med 46(3): 320-330.

7. Pinsolle J, Mauruc B (1990) Cancer of the tongue: etiology diagnosis evolution and prognosis, principles of treatment. Rev Prat 40(19): 18111814.
8. Chomette G, Auriol M (1983) Malignant tumours of the tongue. Anatomopathological aspects. Cervical-facial carcinology news, Tongue cancers. Masson 9: 18-25.

9. Laasibi L (1995) Cancers of the tongue. Thesis Medicine Casablanca, Morocco, North Africa pp. 236

10. Ladgham A, Benjilani S, Sellouz R (1981) Tongue cancers in Tunisia. Maghreb inf Med 8: 22-26.

11. Ferlay J, Steliarova foucher E, Lortet tieulent J (2013) Cancer Incidence and mortality patterns in Europe: Estimates for 40 contries in 2012. European journal of cancer 49(6): 1374-1403.

12. Diombana ML, Mohamed AG, Kussner H, Bayo S, Penneau M (1996) Tongue tumours in the stomatology department of Kati Hospital: about 25 cases. Medicine d Afrique noire 43(8): 478-482.

13. S. Belgadi (2015) Language cancers: a retrospective study of 47 years. Thesis Med Marrakech, Morocco, Africa pp. 71.

14. El Idrissi A (2015) Cancer of the tongue about 24 cases. Thesis of medicine, Fez, Morocco, Africa.

15. El Ouali T (2014) Cancers of the lateral border of the mobile tongue in 7 cases. Medical thesis, Dakar, Senegal, Africa.

16. Aksu G (2006) Treatement results and prognostic factors in oral tongue cancer: analysis of 80 patients. Int J Oral Maxillofac Surg 35: 506-513.

17. Bouyakhef M (2002) Cancers of the mobile tongue. Thesis of Medicine, Casablanca, Morocco, Africa pp. 214.

18. Barthélémy I, Sannajust JP (2005) Cancers of the oral cavity. Preamble, epidemiology, clinical study. EMC Stomatology pp. 277-294.

19. Marshall AF, William WS (2011) Cancer of the oral cavity and oropharynx. Elsevier Masson SAS.

20. Rothman K, Keller A (1972) The effect of joint exposure to alcohol and tobacco on risk of cancer of the mouth and thepharynx. J Chronic Dis 25: 711-716.

21. Laurent B (2006) Cancer of the mobile tongue: prognostic factors for T1-T2 squamous cell carcinomas of the mobile tongue. Medical thesis Nantes.

22. Rakotoarison RA, Ralaiarimanana LF, Alson SR, Razafindrabe JB, Rakotovao FJ (2010) Squamous cell carcinoma of the mobile tongue and irritation of prosthetic-dental origin: about an observation. Med Buccale Chir Buccale 16: 53-56.

23. Menard P, Bertrand JC (1992) Precancerous and cancerous lesions of the oral cavity: their risk factors are well known. Rev Prat 6(187): 39-46.

24. Chassagne JF, Malka G (1988) Cancer of the tongue, cancer of the oral floor, cheeks, lips: etiology, diagnosis, evolution and prognosis, principles of treatment. Rev Prat 38(19): 1327-1333.

25. Mondie JM (1996) Cancer of the tongue: epidemiology, diagnosis, treatment. Rev Prat 46(14): 1775-1781.

26. Brasnu D, Poncet JL, Beauvillain C (2007) Cancer of the mobile tongue. Ann Otolaryngol Chir Cervicofac 124: 244-251.

27. Hicks WL, North JH, Loree TR (1998) Surgery as a single modality therapy for squamous cell carcinoma of the oral tongue. Am J Otolaryngol 19(1): 24-28. 
This work is licensed under Creative Commons Attribution 4.0 License

To Submit Your Article Click Here: Submit Article

DOI: $10.32474 /$ SJ0.2020.03.000174

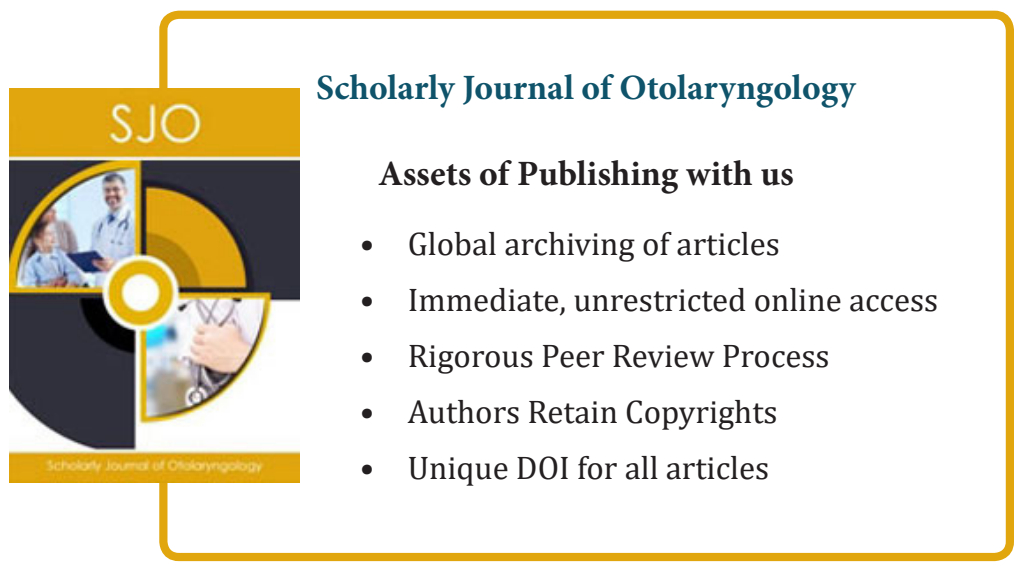

